\title{
Scalable synthesis of 5,11-diethynylated indeno[1,2-b]fluorene-6,12-diones and exploration of their solid state packing
}

\author{
Bradley D. Rose ${ }^{1}$, Peter J. Santa Maria ${ }^{1}$, Aaron G. Fix ${ }^{1}$, Chris L. Vonnegut ${ }^{1}$, \\ Lev N. Zakharov ${ }^{2}$, Sean R. Parkin ${ }^{3}$ and Michael M. Haley ${ }^{* 1}$
}

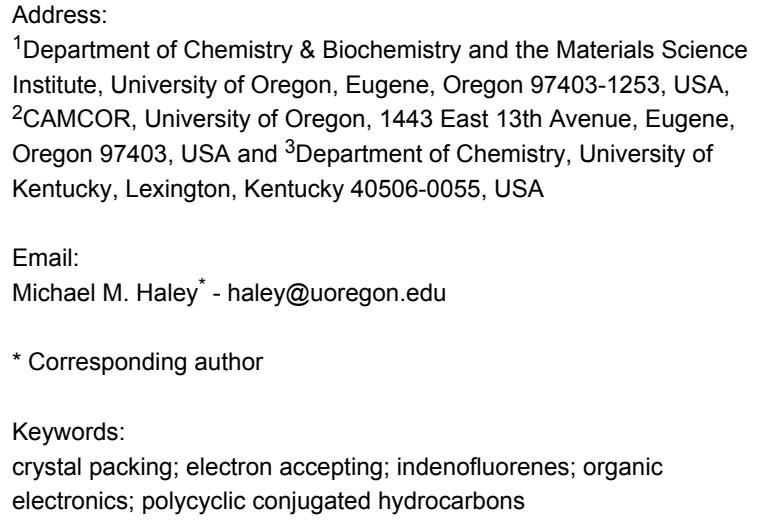

\begin{abstract}
We report a new synthetic route to 5,11-disubstituted indeno[1,2-b]fluorene-6,12-diones that is amenable to larger scale reactions, allowing for the preparation of gram amounts of material. With this new methodology, we explored the effects on crystal packing morphology for the indeno[1,2-b]fluorene-6,12-diones by varying the substituents on the silylethynyl groups.
\end{abstract}

\section{Introduction}

Polycyclic conjugated hydrocarbons (PCHs) have been studied extensively due to the wide variety of physical properties that can be accessed by appropriate manipulation or "tuning" of a molecular scaffold (e.g., installation of donor/acceptor groups, inclusion of heteroatoms, etc.) [1-3]. Recently there has been resurging interest in $\mathrm{PCHs}$ for use as active materials in organic electronic devices. Some popular examples of devices undergoing extensive exploration are organic field effect transistors (OFET) [4,5], organic photovoltaics (OPV) [6], and organic light emitting devices (OLED) [7]. For such devices to operate properly, these must include materials that conduct holes (electron donating) and conduct electrons (electron accepting) [8]. While there are many systems that display high hole mobilities, there are far fewer that exhibit high electron mobilities.

Our laboratory has been exploring a new class of PCHs based on the five structural isomers of indenofluorene [9]. In particular, the indeno[1,2-b]fluorene (IF, 1, Figure 1) skeleton is similar to linear oligoacenes, with the notable exception that the molecule contains two five-membered carbocycles. This modest 
<smiles>[R]C1=c2cc3c(cc2-c2ccccc21)=C([R])c1ccccc1-3</smiles>

$1\left(\mathrm{R}=\mathrm{Ar}, \mathrm{CCSi}(\mathrm{iPr})_{3}\right)$<smiles>O=c1c2c(F)c(F)c(F)c(F)c2c2c(I)c3c(=O)c4c(F)c(F)c(F)c(F)c4c3c(I)c12</smiles>

3

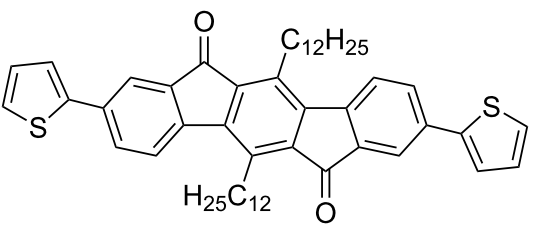

5<smiles>O=c1c2ccccc2c2cc3c(cc12)c(=O)c1ccccc13</smiles>

2<smiles>[X]c1ccc2c(c1)c(=O)c1cc3c(cc12)c(=O)c1cc([X])ccc13</smiles>

$4(\mathrm{X}=\mathrm{F}, \mathrm{Cl}, \mathrm{Br})$

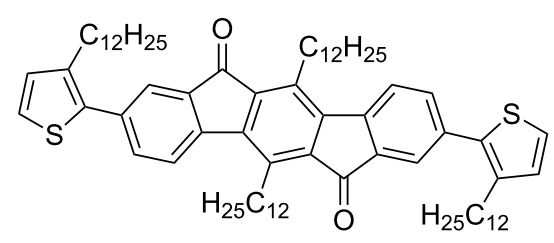

6

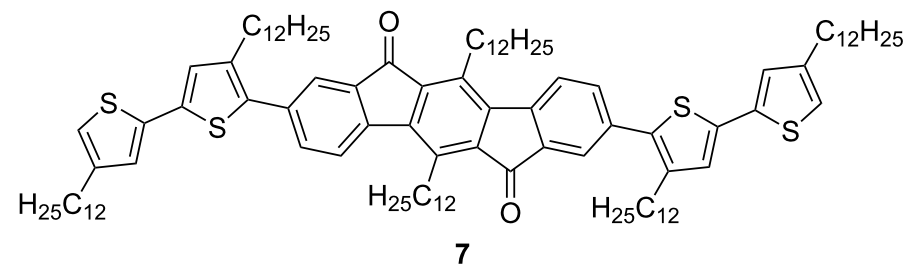

Figure 1: Previously reported indeno[1,2-b]fluorenes and related indeno[1,2-b]fluorene-6,12-diones.

alteration imparts an inherent propensity of the IF scaffold to be electron accepting [10,11]. A simple explanation for the high electron affinity of the IF is that to make all five rings formally aromatic two electrons must be added to the system, effectively creating two cyclopentadiene anions [12]. The result of the IFs high electron affinity is nearly balanced ambipolar charge transport in OFETs [11,13].

The synthetic precursors to $\mathbf{1}$, the indeno[1,2-b]fluorene-6,12diones (IF-diones, 2, Figure 1) have also been explored as an active layer in OFETs. The first reported IF-dione OFET utilized $\mathbf{3}$ - while the solid-state structure of $\mathbf{3}$ showed several sub-van der Waals contact distances, the n-type mobility of the OFET was very low $\left(2 \times 10^{-5} \mathrm{~cm}^{2} \mathrm{~V}^{-1} \mathrm{~s}^{-1}\right)$ [14]. On the other hand, an OFET utilizing $4(\mathrm{X}=\mathrm{F})$ had measured electron mobilities of $0.17 \mathrm{~cm}^{2} \mathrm{~V}^{-1} \mathrm{~s}^{-1}$, and its X-ray crystal structure revealed 1-dimensional $\pi$-stacking with a close interplanar distance of $3.30 \AA[15]$. Due to the inherent insolubility of compounds 3 and 4 , however, they needed to be vapor deposited under vacuum. More recently IF-diones 5-7 were reported (along with polymeric and other derivatives) with 5 and $\mathbf{6}$ exhibiting both $n$ - and p-channel behavior in OFETs [16].
Notably, $\mathbf{6}$ showed balanced hole and electron mobilities when vapor or solution processed. Molecule/polymer solubility is desirable because it offers the benefit of being solution processable, which could allow for the inexpensive large area printing of electronic devices.

We report herein the preparation of a variety of diethynylated IF-diones $\mathbf{8 a}-\mathbf{j}$ that are readily soluble in common organic solvents, and the exploration of their packing in the solid-state by X-ray crystallography. The prototypical molecule that served as inspiration for our studies was pentacene, as it, along with numerous other acene derivatives, has been substituted with trialkylsilylethynyl groups of varying size to study the effect on the solid state packing in single crystals [17]. This was shown to have a large effect on the OFET performance as slight changes in the geometry can dramatically alter the intermolecular electronic coupling, which is what ultimately dictates performance of the device $[18,19]$.

\section{Results and Discussion}

Synthesis. Our initial studies [20] toward 8 (Scheme 1) focused on the Sonogashira cross-coupling of known diiodo intermedi- 


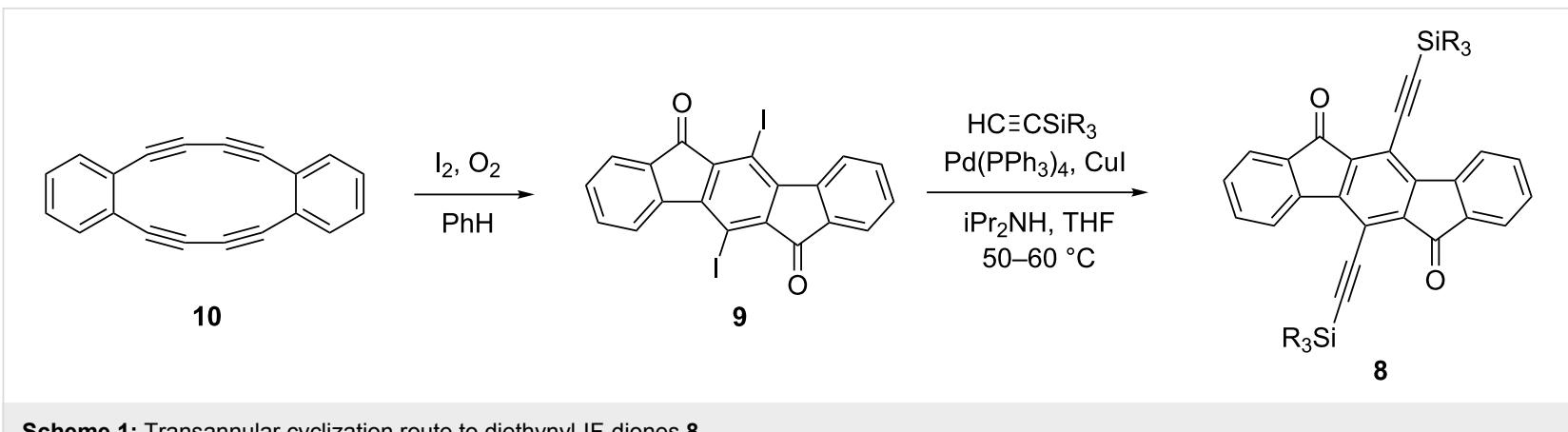

Scheme 1: Transannular cyclization route to diethynyl-IF-diones 8

ate $\mathbf{9}$, which was prepared by double transannular cyclization of 10 using elemental iodine under air [21]. Dehydrobenzo[12]annulene $\mathbf{1 0}$ in turn was synthesized via Glaser homocoupling of 1,2-diethynylbenzene [21-23]. While in theory this route permitted relatively easy access to diethynyldiones $\mathbf{8}$, in practice it was fraught with problems: (1) the formation of $\mathbf{1 0}$ was very sensitive to the reaction conditions and thus typically gave low yields (approx. 10\%) upon scale-up; (2) the reaction must be run in very dilute solution to minimize the formation of larger cyclooligomers as well as polymer; (3) pure $\mathbf{1 0}$ in the solid state is reported to be shock sensitive [22], a fact that we can readily reaffirm; and (4) the iodine atoms on 9 are quite labile as we often observed formation of elemental iodine if solutions of 9 were exposed to heat or sunlight. If we wanted to obtain quantities of diones 8 beyond 20-30 milligrams at a time, we had to overcome the synthetic roadblock that Scheme 1 represented.

The improved synthetic route to $\mathbf{8}$ arises from a retrosynthetic analysis of the current method to prepare IF derivatives $[9-11,13]$. The needed modification must include halogens at the 5 and 11 positions for subsequent functionalization, such as the more robust bromines in $\mathbf{1 1}$, yet avoid annulene transannular synthesis [24]. Instead, the route we chose involved key precursor 12, which surprisingly is an unknown compound. Starting with commercially available 2,5-dibromo- $p$-xylene (13) (Scheme 2), iodination using the method reported by Kitamura gave tetrahalide 12 in good yield on $>10$ g scale [25]. Suzuki cross-coupling with 12 furnished $p$-terphenyl 14, followed by oxidation of the methyl groups to produce diacid 15. Intramolecular Friedel-Crafts acylation then afforded 5,11-dibromo-IFdione 11. The yields for the Sonogashira cross-coupling of a variety of trialkylsilylacetylenes to either $\mathbf{9}$ or $\mathbf{1 1}$ were modest to very good (Table 1) but were not optimized.

Optical and electronic properties. Shown in Figure 2 are the UV-vis spectrum and the cyclic voltammogram of $\mathbf{8 c}$, data that are representative of all the 5,11-diethynyl-IF-diones. As anticipated, altering the trialkylsilyl group has very little effect on the

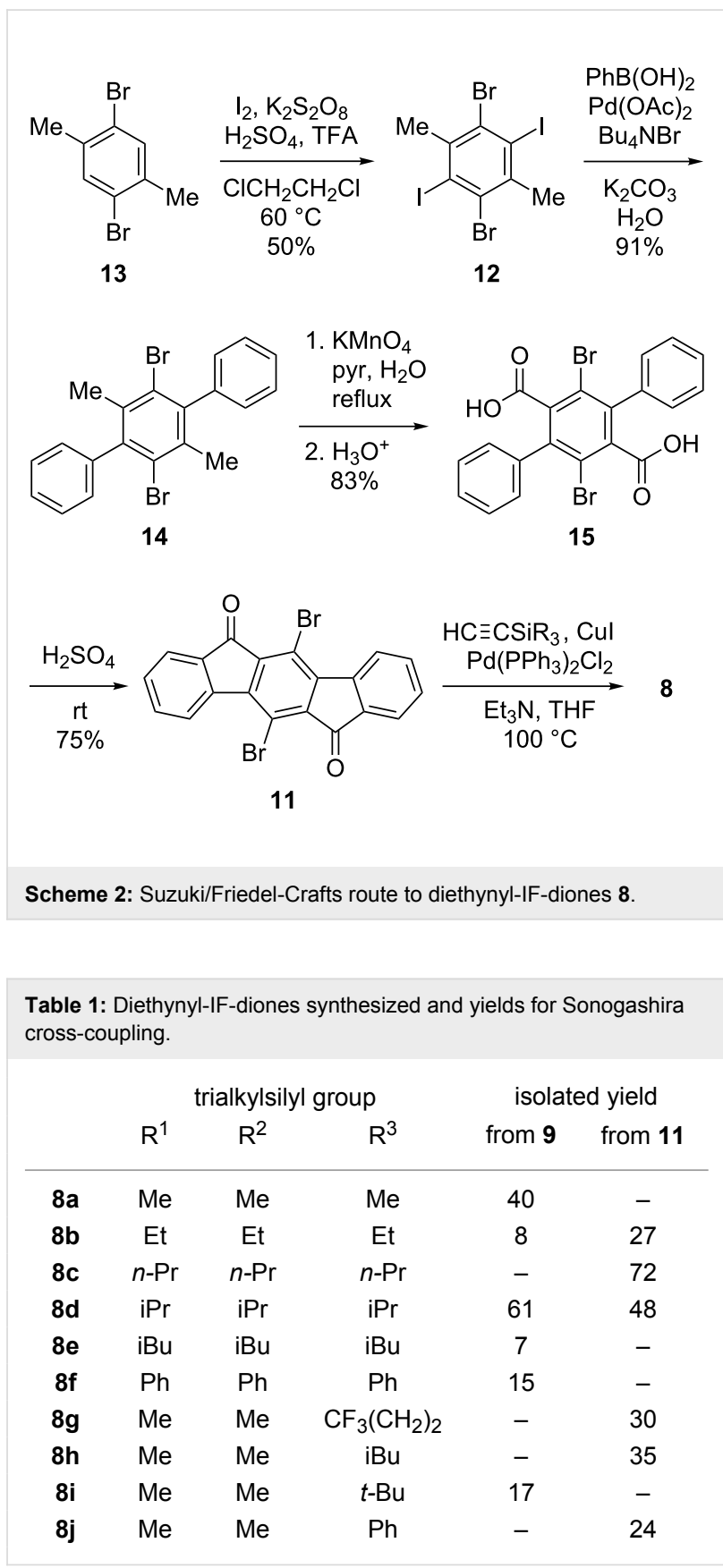




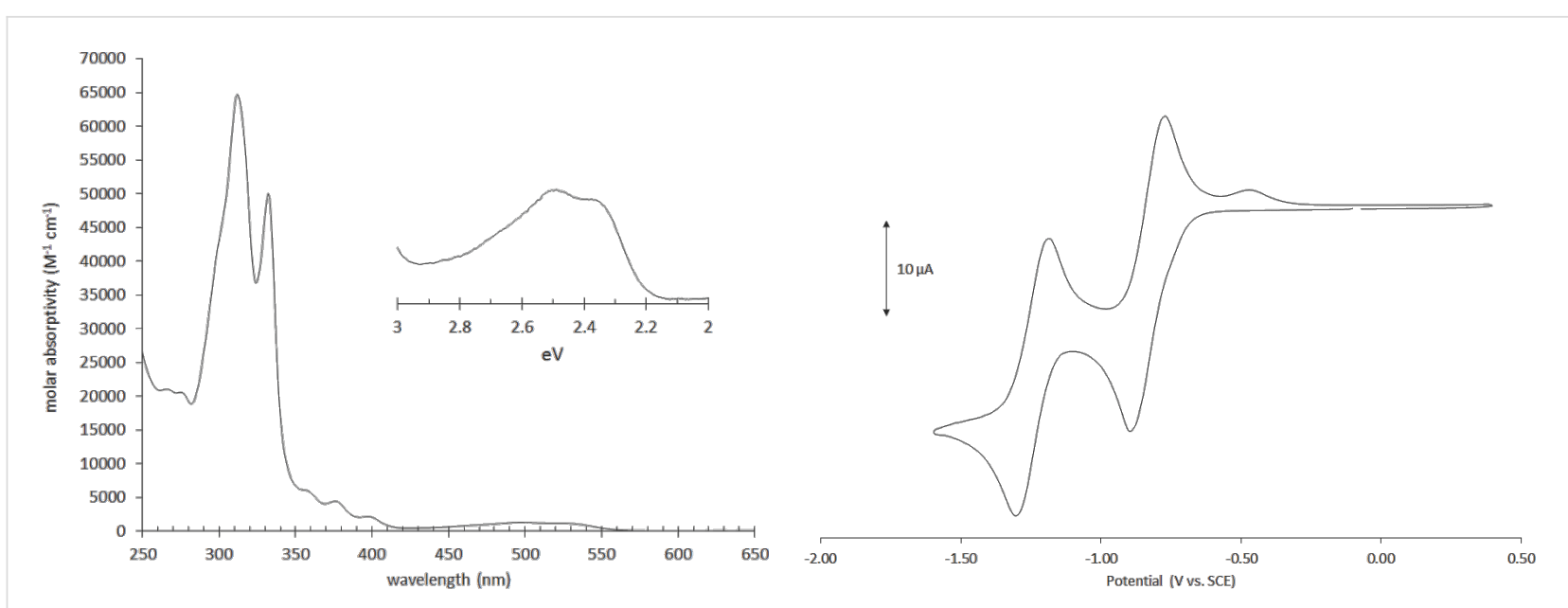

Figure 2: UV-vis spectrum (left) and cyclic voltammogram (right) of dione 8c.

optoelectronic properties of the conjugated scaffold (Table 2). All molecules have two strong absorptions around 310 and $330 \mathrm{~nm}$, with a much weaker, broad absorption in the $450-550 \mathrm{~nm}$ range. Electrochemistry shows two reversible reductions with potentials of -0.78 to $-0.84 \mathrm{~V}$ for the first reduction and -1.18 to $-1.26 \mathrm{~V}$ for the second reduction. The small differences in the absorbance and cyclic voltammetry essentially fall within experimental error.

Interestingly these compounds have a low energy $\mathrm{S}_{0} \rightarrow \mathrm{S}_{1}$ transition at ca. 500-525 nm which has previously and incorrectly been described as an $n \rightarrow \pi^{*}$ transition [16,20]; however, TD-DFT calculations predict this to be $\pi \rightarrow \pi^{*}$ (Figure 3 ) $[27,28]$. The $n \rightarrow \pi^{*}$ transition was calculated to have a slightly higher energy transition with an oscillator strength of 0 ; thus, it should not be visible in the UV-vis spectrum (Table 3). To see if this was a computational artifact, the same calculations were performed for fluorenone and benzophenone, where it has previously been established that the $\mathrm{S}_{0} \rightarrow \mathrm{S}_{1}$ transition corresponds to $\pi \rightarrow \pi^{*}$ and $n \rightarrow \pi^{*}$, respectively [29,30]. The calculations correctly predict the ordering of the states for fluorenone and benzophenone. To validate this experimentally, UV-vis spectra were gathered in solvents of differing polarity. We anticipated that if the $S_{0} \rightarrow S_{1}$ transition corresponds to a $n \rightarrow \pi^{*}$ transition, the energy separating the $S_{0}$ and $S_{1}$ states would be measurably different in polar solvents when compared to nonpolar solvents, thus leading to an energy shift of this transition. Likewise if the $\mathrm{S}_{0} \rightarrow \mathrm{S}_{1}$ transition was a $\pi \rightarrow \pi^{*}$ there should be essentially no change in the transition energy when changing solvent polarity. We found that the shift in the spectrum upon

Table 2: Electrochemical and optical data for ID-diones 8a-j

\begin{tabular}{|c|c|c|c|c|c|c|}
\hline \multirow[b]{2}{*}{ compd } & \multicolumn{4}{|c|}{ electrochemical $^{a}$} & \multicolumn{2}{|c|}{ optical } \\
\hline & $E_{\text {red }}^{1}(\mathrm{~V})$ & $E_{\mathrm{red}^{2}}(\mathrm{~V})$ & $E_{\mathrm{LUMO}}(\mathrm{eV})^{\mathrm{b}}$ & $E_{\mathrm{HOMO}}(\mathrm{eV})^{\mathrm{c}}$ & $\lambda_{\mathrm{abs}}(\mathrm{nm})$ & gap $(e V)^{d}$ \\
\hline $8 a$ & -0.80 & -1.21 & -3.89 & -6.26 & $310,330,524$ & 2.37 \\
\hline $8 b$ & -0.79 & -1.23 & -3.90 & -6.28 & $311,332,522$ & 2.38 \\
\hline $8 c$ & -0.83 & -1.24 & -3.86 & -6.23 & $312,332,524$ & 2.37 \\
\hline $8 d$ & -0.82 & -1.24 & -3.87 & -6.23 & $313,333,525$ & 2.36 \\
\hline $8 e$ & -0.84 & -1.26 & -3.85 & -6.22 & $314,333,524$ & 2.37 \\
\hline $8 f$ & -0.78 & -1.18 & -3.90 & -6.29 & $312,333,520$ & 2.39 \\
\hline $8 g$ & -0.77 & -1.18 & -3.87 & -6.27 & $308,330,516$ & 2.40 \\
\hline $8 \mathrm{~h}$ & -0.78 & -1.21 & -3.86 & -6.24 & $310,331,521$ & 2.38 \\
\hline $8 \mathbf{i}$ & -0.81 & -1.25 & -3.87 & -6.23 & $312,331,526$ & 2.36 \\
\hline $8 \mathbf{j}$ & -0.78 & -1.20 & -3.86 & -6.24 & $310,331,521$ & 2.38 \\
\hline
\end{tabular}

${ }^{a} \mathrm{CV}$ recorded using 1-5 mM of analyte in $0.1 \mathrm{M}$ solution of either $\mathrm{Bu}_{4} \mathrm{NOTf}(\mathbf{8 a}, \mathbf{8 b}, \mathbf{8 d}-\mathbf{f}, \mathbf{8 i})$ or $\mathrm{Bu}_{4} \mathrm{NBF}_{4}(\mathbf{8 c}, \mathbf{8 g}, \mathbf{8 h}, \mathbf{8 j})$ in HPLC-grade CH $\mathrm{HCl}_{2}$. Values reported as the half-wave potential (vs SCE) using the $\mathrm{Fc} / \mathrm{Fc}^{+}$couple $(0.46 \mathrm{~V})$ as an internal standard. See Supporting Information File 1 for

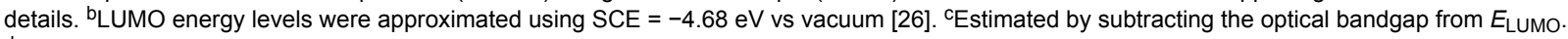
dEstimated from the $\lambda_{\max }$ of the lowest energy UV-vis peak. 

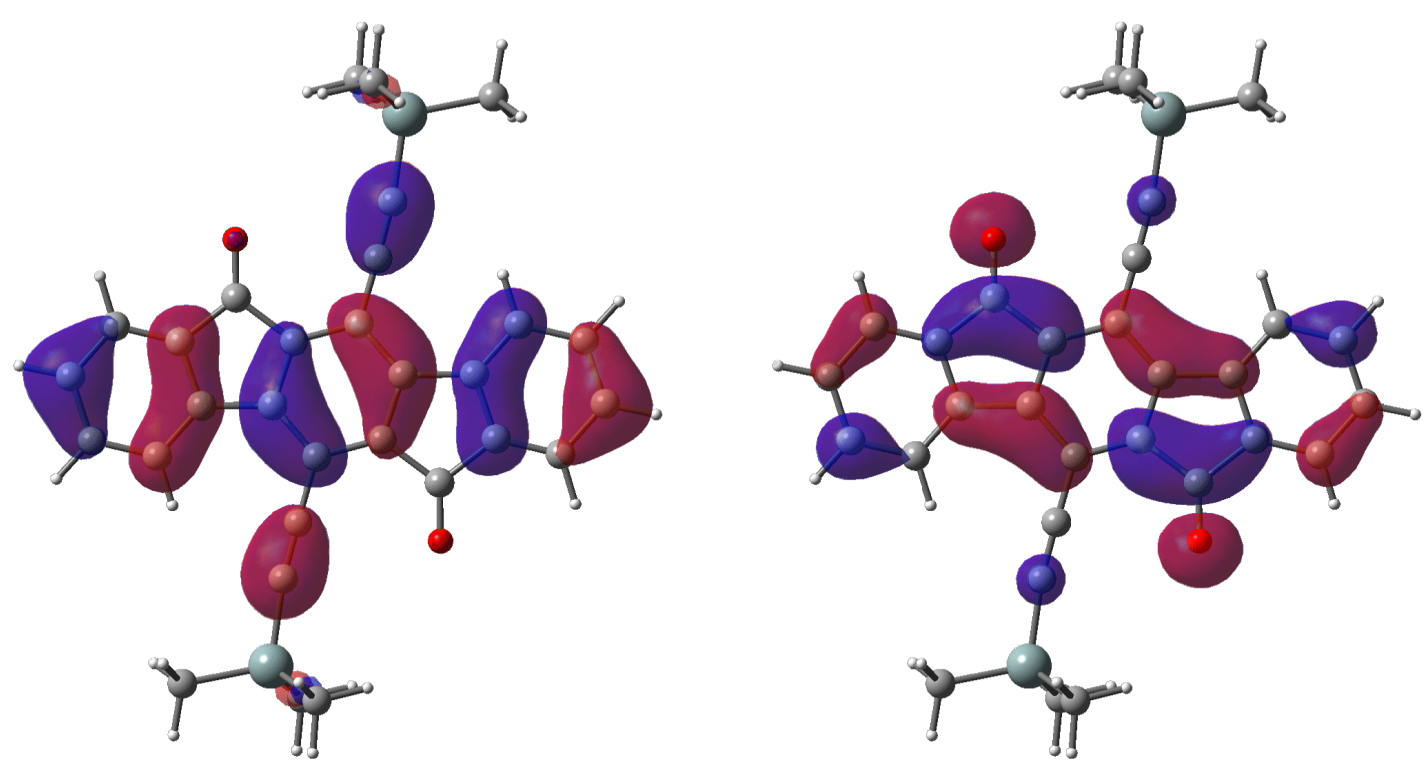

Figure 3: Kohn-Sham HOMO (left) and LUMO (right) plots of $\mathbf{8 a}$.

Table 3: Calculated transitions for 8a, showing only the main contribution to each excitation. Calculated using TD-B3LYP/6-311+G(d,p)//B3LYP/6$31 \mathrm{G}(\mathrm{d})$.

\begin{tabular}{cccc} 
transition & molecular orbitals & $\begin{array}{c}\text { contribution to } \\
\text { excitation, } \%\end{array}$ & oscillator strength \\
\hline$S_{0} \rightarrow S_{1}$ & HOMO $\rightarrow$ LUMO & 97 & 0.0295 \\
$S_{0} \rightarrow S_{2}$ & HOMO-2 $\rightarrow$ LUMO & 89 & 0.0000 \\
$S_{0} \rightarrow S_{3}$ & HOMO-3 $\rightarrow$ LUMO & 80 & 0.0000 \\
$S_{0} \rightarrow S_{4}$ & HOMO-1 $\rightarrow$ LUMO & 88 & 0.0486
\end{tabular}

changing solvent polarity in going from $n$-hexane to acetone was $0.02 \mathrm{eV}$, supporting our hypothesis that the $450-550 \mathrm{~nm}$ absorption is indeed a $\pi \rightarrow \pi^{*}$ transition as indicated by calculations.

X-ray crystallography. We explored the solid-state packing geometries resulting from altering the substitution on the silyl groups. The high crystallinity of the majority of the compounds examined permitted facile growth of large single crystals, of approximately several millimeters, from hexanes solution. Single crystals for $\mathbf{8 g}$ and $\mathbf{8 j}$ were grown from chlorobenzene due to the low solubility and crystallinity of these compounds. The molecular structures were then elucidated using x-ray diffraction.

The ten compounds $\mathbf{8 a}-\mathbf{j}$ exhibit several different packing motifs (Figure 4). In a broad sense, the progression in packing follows a trend with the volume of the substituted silyl groups $[31,32]$. Segregation of the IF-dione backbone and the solubi- lizing groups, and $\pi$-stacking is observed in all but the largest $\left(\mathbf{8 f}, \mathrm{SiPh}_{3}\right)$, but there are significant differences in the nature of the $\pi$-stacking of the other nine compounds. The smallest (8a, $\mathrm{SiMe}_{3}$, vol. $\sim 130 \AA^{3}$ ) is monoclinic, $P 2_{1} / \mathrm{c}$, with a unit cell elongated along $b$. The molecules form 1-D $\pi$-stacks (interplanar spacing 3.446(5) $\AA$ ) parallel to $a$, with adjacent stacks having the opposite tilt by virtue of the $c$-glide, leading to a herringbone motif in which inter-stack interactions are solely between the $\mathrm{SiMe}_{3}$ groups. This is the only structure of this type in the group of ten compounds. The next largest $\mathbf{8 g}$, $\mathrm{SiMe}_{2} \mathrm{PrF}_{3}$, vol. $\sim 198 \AA^{3}$ ) is orthorhombic, $P \mathrm{ca}{ }_{1}$, with a squat unit cell (short $b$ axis). Molecules form 1-D $\pi$-stacks parallel to the $b$-axis (interplanar spacing 3.358(3) $\AA$ ), while adjacent stacks interact via $\mathrm{C}-\mathrm{H} \cdots \pi$ contacts to form herringbonepatterned layers (interstack molecular tilt $66.85(2)^{\circ}$ ) in the $a b$ plane, separated by layers of fluorinated 'grease'. Compounds $\mathbf{8 b}, \mathbf{8 i}$ and $\mathbf{8 h}$, which have essentially the same volume solubilizing groups $\left(\sim 204 \AA^{3}\right)$, exhibit very similar overall packing motifs. They are monoclinic, $P 2_{1} / \mathrm{c}$, with squat unit cells (short 

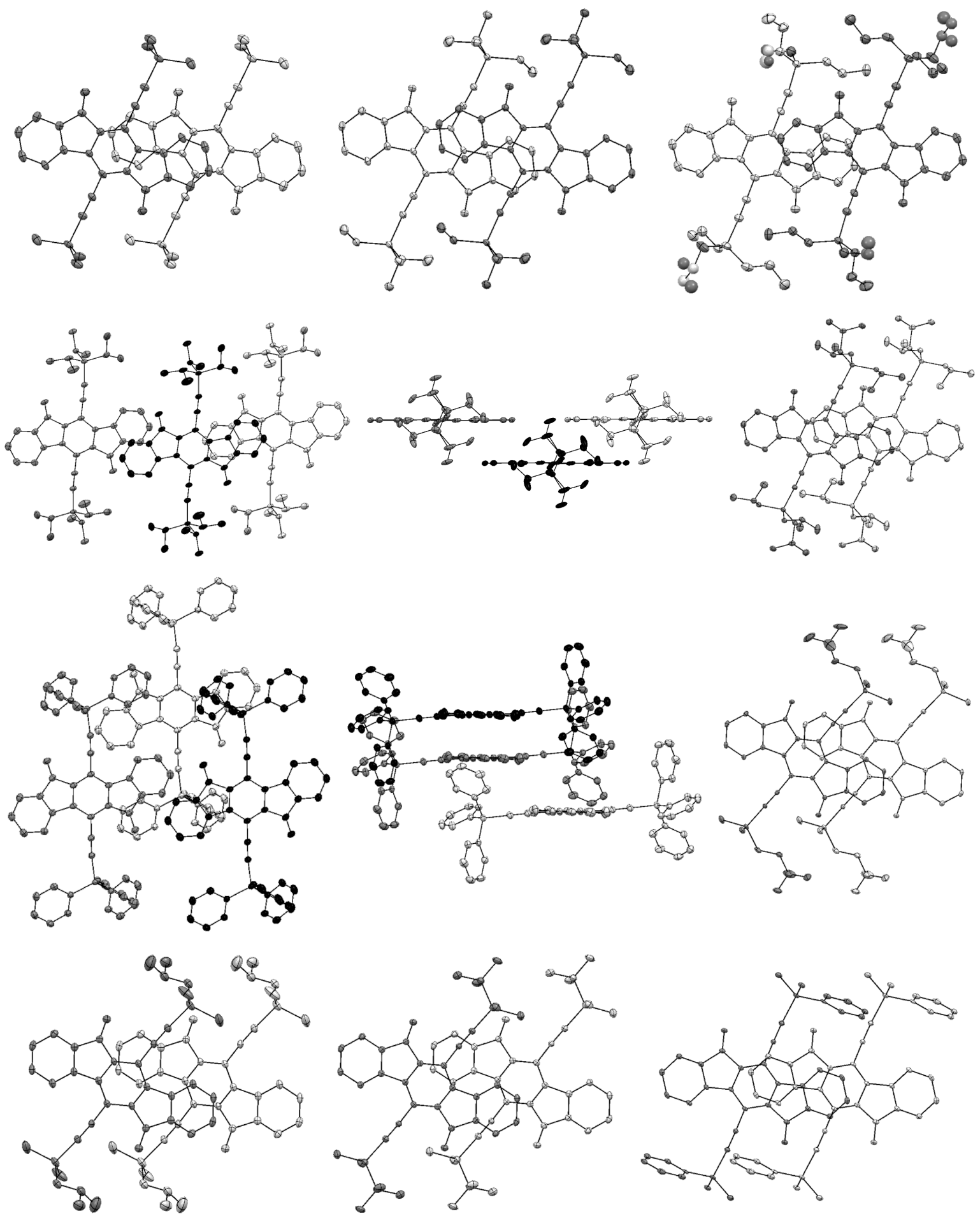

Figure 4: Views perpendicular to the average plane of the $\pi$ stack. $1^{\text {st }}$ row left to right $-\mathbf{8 a}, \mathbf{8 b}, \mathbf{8 c} ; 2^{\text {nd }}$ row $-\mathbf{8 d}, \mathbf{8 d}, \mathbf{8 e} ; 3^{\text {rd }}$ row $-\mathbf{8 f}, \mathbf{8 f}, \mathbf{8 g} ; 4^{\text {th }}$ row $\mathbf{8 h}, \mathbf{8 i}, \mathbf{8 j}$. Hydrogen atoms omitted for clarity; ellipsoids drawn at the $30 \%$ probability; individual molecules were colored the same to identify overlap easier.

$b$ axis), and form 1-D $\pi$-stacks parallel to $b$ (interplanar spacings of 3.454(2) $\AA, 3.340(2) \AA$ and 3.385(3) $\AA$, respectively, for $\mathbf{8 b}, \mathbf{8 i}$ and $\mathbf{8 h}$ ). Adjacent stacks along $c$ interact via $\mathrm{C}-\mathrm{H} \cdots \pi-$ contacts, and are related by the $c$-glide operation to form the common herringbone motif (interstack molecular tilts of $64.88(2)^{\circ}, 64.45(2)^{\circ}$ and $68.99(3)^{\circ}$, respectively, for $\mathbf{8 b}, \mathbf{8 i}$ and 
8h). These $b c$ layers are separated by layers of trialkylsilyl groups. Compound $\mathbf{8 j}$ has a slightly larger $\left(\sim 210 \AA^{3}\right)$ solubilizing group, but is triclinic, $P \overline{1}$. The difference in crystal symmetry compared to $\mathbf{8 b}, \mathbf{8 i}, \mathbf{8 h}$ (and to $\mathbf{8 g}$ ), however, belies the similarities. The unit cell is a squat skewed box (short $a$-axis, though easily transformed to a short $b$ setting that makes the similarity to $\mathbf{8 b}, \mathbf{8 i}, \mathbf{8 h}$ clearer). There are two half molecules per asymmetric unit, each sitting on inversion centers. Crystallographically identical molecules form 1-D $\pi$-stacks along the short $a$-axis ( $c f$ short $b$-axis in $\mathbf{8 b}, \mathbf{8 i}, \mathbf{8 h}, \mathbf{8 g}$ ), leading to two independent molecular $\pi$-stacks, which have slightly different interlayer spacings (3.385(2) $\AA$ and 3.397(2) $\AA$ ). Between adjacent stacks, the crystallographically independent molecules are tilted relative to each other by $66.88(2)^{\circ}$, giving a variant of the common herringbone motif, despite the lack of a crystallographic glide plane. In addition to the IF-dione $\pi$-stacking, inversion-related phenyl groups on the solubilizing groups are paired by $\pi-\pi$ interactions. The stacking in compounds $8 \mathbf{c}$ and $\mathbf{8 d}\left(\mathrm{Si}(n-\mathrm{Pr})_{3}\right.$ and $\mathrm{Si}(\mathrm{iPr})_{3}$, vol. $\left.\sim 278 \AA^{3}\right)$ are similar at first glance. In $\mathbf{8 c}$, each end of the IF-dione backbone overlaps by different amounts with adjacent molecules (interplanar spacings of 3.422(3) $\AA$ and 3.446(4) $\AA$ ) to form a 2-D $\pi$-stacked brickwork motif. In $\mathbf{8 d}$, the superficially similar $\pi$-stacking motif is better described as a $1-\mathrm{D} \pi$-stack. There is significant overlap between adjacent molecules on only one side (interlayer spacing = 3.404(3) $\AA$ ), while on the other side, any 'overlap' amounts to only the mutual superposition of $\mathrm{C} 10$ over the $\mathrm{C} 5-\mathrm{C} 10$ bond of the neighboring molecule. Moreover, a rudimentary superposition of the LUMO plots (Figure 3) for the relative positions of this molecular pair arrangement suggests no favorable orbital interactions. In $8 \mathbf{e}\left(\mathrm{Si}(\mathrm{iBu})_{3}\right.$, vol. $\left.\sim 353 \AA^{3}\right)$, the structure is monoclinic, $P 2_{1} / \mathrm{n}$. The IF-dione molecules form 1 -D $\pi$-stacks (interplanar spacing $=3.394(2) \AA$ ) that are completely segregated from neighboring stacks by the bulky $\mathrm{Si}(\mathrm{iBu})_{3}$ groups. The largest group, $\mathrm{SiPh}_{3}\left(\right.$ vol. $\left.\sim 372 \AA^{3}\right)$ in $\mathbf{8 f}$, effectively suppresses overlap of the IF-dione backbones between adjacent molecules.

There are three distinct substitution patterns in the array of IF-diones synthesized - (1) the three groups are $n$-alkyl chains with symmetry (three mirror symmetry planes about the silicon), (2) bulky alkyl groups with symmetry, and (3) dimethyl-substituted possessing only one mirror plane of symmetry about the silicon. When looking further for trends, we compared two parameters to see if any of them ultimately yielded packing motifs with close contacts between the carbons of the conjugated system. One parameter examined is the distance between the centroid of the planar system and its next nearest neighbor along the one-dimensional $\pi$ stack. The other parameter is the angle between the centroids of the nearest neighbor molecules and the normal to the plane of a molecule; thus, a system with maximum overlap would have $\theta=0^{\circ}$, while $\theta=90^{\circ}$ would result in no $\pi$ orbital overlap. Using these two parameters a crude model for examining the possible intermolecular electronic coupling can be developed, which is pictorially represented in Figure 5.

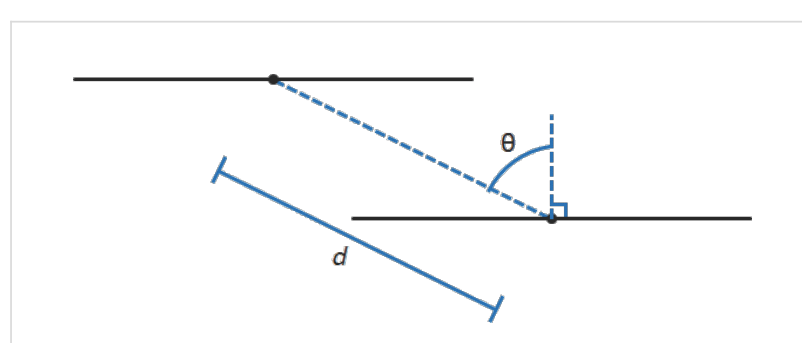

Figure 5: Schematic of the parameters used for comparing X-ray crystal structures, view is parallel to the molecular plane. Black lines represent the molecules with circles denoting the centroid.

Looking at Table 4 the only visible trend in the series appears to be within the $n$-alkyl symmetric. The $n$-alkyl symmetric series has both the $d$ and $\theta$ follow the trend of the alkyl group's radius. When examining symmetric and asymmetric series there is not an easily interpretable trend between the radii and $d$ or $\theta$. Pictorially the overlap between the molecular planes is clearly visible in Figure 5. For the $n$-alkyl symmetric series visual inspection reveals that the overlap between the planes of the molecules is greatest for the smallest group, 8a, and least for the largest group, $\mathbf{8 c}$. Yet again, there is no clear visual trend in the overlap between the symmetric and asymmetric series. Considering that derivatives of $\mathbf{8}$ are most likely an n-channel material in OFETs, the density and phase of the LUMO should be the most important since in a molecular orbital picture of charge transport these are the orbitals that the extra electron would occupy. The Kohn-Sham LUMO density in Figure 3 is predominately located on the indacene moiety and the oxygen. From this perspective the best candidates for n-channel OFET materials would have large overlap between the indacene moiety and oxygen. In $\mathbf{8 a}-\mathbf{j}$ the oxygen is pointing away from the indacene moiety in the neighboring molecules along the stack and there is little to no overlap between the indacene moieties.

\section{Conclusion}

We have described an improved synthetic route to 5,11diethynyl-functionalized indeno[1,2- $b]$ fluorene-6,12-diones that permits a scalable synthesis of larger amounts of material. We explored the solid state packing motifs that result from altering the bulkiness as well as directionality of the trialkylsilyl groups. Altering the substitution on the silyl group had little, if any, effect on the electronic properties of $\mathbf{8}$, which are dominated by the conjugated core; however, there were marked differences in the solid-state packing of single crystals of these compounds. 
Table 4: Sizes of trisubstituted-silylethynyl groups in $\mathbf{8}$.

\begin{tabular}{|c|c|c|c|c|c|c|c|}
\hline & \multicolumn{7}{|c|}{ intermolecular close contacts } \\
\hline & & $\begin{array}{l}\text { radius } \\
(\AA)^{a}\end{array}$ & $\begin{array}{l}\text { radius } \\
(\AA)^{b}\end{array}$ & contact & distance $(\AA)$ & $d^{C}$ & $\theta^{\mathrm{d}}$ \\
\hline \multirow[t]{3}{*}{$n$-alkyl symmetric } & $8 \mathbf{a}$ & 2.69 & - & - & - & 6.366 & 57.2 \\
\hline & $8 b$ & 4.06 & - & - & - & 6.439 & 57.5 \\
\hline & $8 \mathrm{c}$ & 5.26 & - & - & - & 8.239 & 65.4 \\
\hline \multirow[t]{6}{*}{ symmetric } & $8 a$ & 2.69 & - & - & - & 6.366 & 57.2 \\
\hline & $8 b$ & 4.06 & - & - & - & 6.439 & 57.5 \\
\hline & $8 d$ & 4.09 & - & - & - & $9.550,7.419^{e}$ & $69.6,62.7^{e}$ \\
\hline & $8 c$ & 5.26 & - & - & - & 8.239 & 65.4 \\
\hline & $8 e$ & 5.28 & - & $\begin{array}{l}\text { C9 } \cdots \text { C2 } \\
\text { C6 } \cdots \text { C3 } \\
\text { C6 } 6 \cdots \text { C6 }\end{array}$ & $\begin{array}{l}3.407 \\
3.562 \\
3.524\end{array}$ & 6.134 & 56.4 \\
\hline & $8 f$ & 5.89 & - & 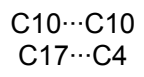 & $\begin{array}{l}3.188 \\
3.369\end{array}$ & 10.984 & 74.7 \\
\hline \multirow[t]{4}{*}{ asymmetric } & $8 \mathbf{i}$ & 2.73 & 3.99 & $\mathrm{C} 7 \cdots \mathrm{C} 3$ & 3.348 & 6.356 & 58.0 \\
\hline & $8 h$ & 2.68 & 5.26 & 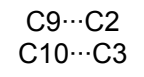 & $\begin{array}{l}3.437 \\
3.409\end{array}$ & 5.976 & 55.3 \\
\hline & $8 \mathrm{~g}$ & 2.67 & 5.74 & $\begin{array}{l}\text { C6 } \cdots \text { C10 } \\
\text { C3 } \cdots \text { C17 }\end{array}$ & $\begin{array}{l}3.361 \\
3.361\end{array}$ & 6.096 & 56.5 \\
\hline & $8 \mathbf{j}$ & 2.68 & 5.94 & - & - & 6.292 & 57.3 \\
\hline
\end{tabular}

${ }^{a} \mathrm{~S} i \cdots X$ distance where $\mathrm{X}$ is the farthest atom from Si with the covalent radii of $\mathrm{X}$ added to the distance [30]. ${ }^{\mathrm{b}}$ Radius for other axis of lower symmetry trialkylsilanes. 'Distance between the centroid of two molecules in the 1-D stack. ${ }^{d}$ Angle between the centroid of each of two molecules of the $\pi$ stack

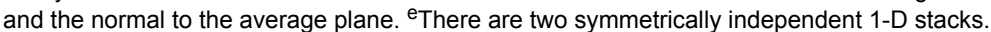

Unfortunately, from a zeroth order approximation none of the variants displayed promising intermolecular electronic coupling.

\section{Supporting Information}

\section{Supporting Information File 1}

Experimental procedures, computational details and xyz coordinates, X-ray information including CCDC numbers and copies of ${ }^{1} \mathrm{H}$ and ${ }^{13} \mathrm{C}$ NMR spectra.

[http://www.beilstein-journals.org/bjoc/content/ supplementary/1860-5397-10-219-S1.pdf]

\section{Acknowledgements}

We thank the National Science Foundation (CHE-1013032 \& CHE-1301485) for support of this research. B.D.R. acknowledges the American Chemical Society Division of Organic Chemistry for an Emmanuil Troyanski Fellowship as well as the NSF for a GK-12 Fellowship (DGE-0742540). P.J.S.M. acknowledges the NSF for an REU Summer Fellowship (CHE1062512). We thank Dr. Johannes Gierschner for initial discussions regarding the photophysics of the IF-6,12-diones as well as Prof. John Anthony for helpful discussions of molecule packing.

\section{References}

1. Balaban, A. T.; Banciu, M.; Ciorba, V. Annulenes, Benzo-, Hetero-, Homo-Derivatives and their Valence Isomers; CRC Press: Boca Raton, Florida, 1987.

2. Hopf, H. Classics in Hydrocarbon Chemistry: Syntheses, Concepts, Perspectives; Wiley-VCH: Weinheim, Germany, 2000.

3. Harvey, R. G. Polycyclic Aromatic Hydrocarbons; Wiley-VCH: New York, 1997.

4. Zaumseil, J.; Sirringhaus, H. Chem. Rev. 2007, 107, 1296-1323. doi:10.1021/cr0501543

5. Di, C.; Zhang, F.; Zhu, D. Adv. Mater. 2013, 25, 313-330. doi:10.1002/adma.201201502

6. Schlenker, C. W.; Thompson, M. E. Top. Curr. Chem. 2012, 312, 175-212. doi:10.1007/128_2011_219

7. Xiao, L.; Chen, Z.; Qu, B.; Luo, J.; Kong, S.; Gong, Q.; Kido, J. Adv. Mater. 2011, 23, 926-952. doi:10.1002/adma.201003128

8. Sun, S.-S.; Dalton, L. R., Eds. Introduction to Organic Electronic and Optoelectronic Materials and Devices; CRC Press: Boca Raton, Florida, 2008.

9. Fix, A. G.; Chase, D. T.; Haley, M. M. Top. Curr. Chem. 2012. doi:10.1007/128_2012_376

10. Chase, D. T.; Fix, A. G.; Rose, B. D.; Weber, C. D.; Nobusue, S.; Stockwell, C. E.; Zakharov, L. N.; Lonergan, M. C.; Haley, M. M. Angew. Chem., Int. Ed. 2011, 50, 11103-11106. doi:10.1002/anie.201104797

11. Chase, D. T.; Fix, A. G.; Kang, S. J.; Rose, B. D.; Weber, C. D.; Zhong, Y.; Zakharov, L. N.; Lonergan, M. C.; Nuckolls, C.; Haley, M. M. J. Am. Chem. Soc. 2012, 134, 10349-10352. doi:10.1021/ja303402p 
12. Rose, B. D.; Sumner, N. J.; Filatov, A. S.; Peters, S. J.; Zakharov, L. N.; Petrukhina, M. A.; Haley, M. M. J. Am. Chem. Soc. 2014, 136, 9181-9189. doi:10.1021/ja503870z

13. Nishida, J.; Tsukaguchi, S.; Yamashita, Y. Chem. - Eur. J. 2012, 18, 8964-8970. doi:10.1002/chem.201200591

14. Miyata, Y.; Minari, T.; Nemoto, T.; Isoda, S.; Komatsu, K. Org. Biomol. Chem. 2007, 5, 2592-2598. doi:10.1039/b706621j

15. Nakagawa, T.; Kumaki, D.; Nishida, J.; Tokito, S.; Yamashita, Y. Chem. Mater. 2008, 20, 2615-2617. doi:10.1021/cm800366b

16. Usta, H.; Risko, C.; Wang, Z.; Huang, H.; Deliomeroglu, M. K.; Zhukhovitskiy, A.; Facchetti, A.; Marks, T. J. J. Am. Chem. Soc. 2009, 131, 5586-5608. doi:10.1021/ja809555c

17. Anthony, J. E. Angew. Chem., Int. Ed. 2008, 47, 452-483. doi:10.1002/anie.200604045

18. Anthony, J. E.; Brooks, J. S.; Eaton, D. L.; Parkin, S. R. J. Am. Chem. Soc. 2001, 123, 9482-9483. doi:10.1021/ja0162459

19. Coropceanu, V.; Li, Y.; Yi, Y.; Zhu, L.; Bredas, J.-L. MRS Bull. 2013, 38, 57-64. doi:10.1557/mrs.2012.313

20. Rose, B. D.; Chase, D. T.; Weber, C. D.; Zakharov, L. N.; Lonergan, M. C.; Haley, M. M. Org. Lett. 2011, 13, 2106-2109. doi:10.1021/ol200525g

21.Zhou, Q.; Carroll, P. J.; Swager, T. M. J. Org. Chem. 1994, 59, 1294-1301. doi:10.1021/jo00085a016

22. Behr, O. M.; Eglinton, G.; Galbraith, A. R.; Raphael, R. A. J. Chem. Soc. 1960, 3614-3625. doi:10.1039/jr9600003614

23. Bunz, U. H. F.; Enkelmann, V. Chem. - Eur. J. 1999, 5, 263-266. doi:10.1002/(SICI)1521-3765(19990104)5:1<263::AID-CHEM263>3.0. CO;2-X

24. Takeda, T.; Inukai, K.; Tahara, K.; Tobe, Y. J. Org. Chem. 2011, 76, 9116-9121. doi:10.1021/jo2014593

25. Rahman, M. A.; Shito, F.; Kitamura, T. Synthesis 2010, 27-29. doi:10.1055/s-0029-1217072

26. Reiss, H.; Heller, A. J. Phys. Chem. 1985, 89, 4207-4213. doi:10.1021/j100266a013

27. Frisch, M. J.; Trucks, G. W.; Schlegel, H. B.; Scuseria, G. E.; Robb, M. A.; Cheeseman, J. R.; Scalmani, G.; Barone, V.; Mennucci, B.; Petersson, G. A.; Nakatsuji, H.; Caricato, M.; Li, X.; Hratchian, H. P.; Izmaylov, A. F.; Bloino, J.; Zheng, G.; Sonnenberg, J. L.; Hada, M.; Ehara, M.; Toyota, K.; Fukuda, R.; Hasegawa, J.; Ishida, M.; Nakajima, T.; Honda, Y.; Kitao, O.; Nakai, H.; Vreven, T.; Montgomery, Jr., J. A.; Peralta, J. E.; Ogliaro, F.; Bearpark, M.; Heyd, J. J.; Brothers, E.; Kudin, K. N.; Staroverov, V. N.; Kobayashi, R.; Normand, J.; Raghavachari, K.; Rendell, A.; Burant, J. C.; Iyengar, S. S.; Tomasi, J.; Cossi, M.; Rega, N.; Millam, N. J.; Klene, M.; Knox, J. E.; Cross, J. B.; Bakken, V.; Adamo, C.; Jaramillo, J.; Gomperts, R.; Stratmann, R. E.; Yazyev, O.; Austin, A. J.; Cammi, R.; Pomelli, C.; Ochterski, J. W.; Martin, R. L.; Morokuma, K.; Zakrzewski, V. G.; Voth, G. A.; Salvador, P.; Dannenberg, J. J.; Dapprich, S.; Daniels, A. D.; Farkas, Ö.; Foresman, J. B.; Ortiz, J. V.; Cioslowski, J.; Fox, D. J. Gaussian 09, Revision C.01; Gaussian Inc., Wallingford CT, 2010.

28. Dennington, R.; Keith, T.; Millam, J. GaussView 5; Semichem Inc.: Shawnee Mission KS, 2009.

29. Yoshihara, K.; Kearns, D. R. J. Chem. Phys. 1966, 45, 1991-1999. doi:10.1063/1.1727883

30. Dilling, W. L. J. Org. Chem. 1966, 31, 1045-1050. doi:10.1021/jo01342a014

31. Cordero, B.; Gómez, V.; Platero-Prats, A. E.; Revés, M.; Echeverria, J.; Cremades, E.; Barragán, F.; Alvarez, S. Dalton Trans. 2008, 2832-2838. doi:10.1039/b801115j

32. http://xray.uky.edu/internal/course/extras/atomic_volumes.pdf.

\section{License and Terms}

This is an Open Access article under the terms of the Creative Commons Attribution License

(http://creativecommons.org/licenses/by/2.0), which permits unrestricted use, distribution, and reproduction in any medium, provided the original work is properly cited.

The license is subject to the Beilstein Journal of Organic Chemistry terms and conditions:

(http://www.beilstein-journals.org/bjoc)

The definitive version of this article is the electronic one which can be found at: doi:10.3762/bjoc. 10.219 